LOPES, Manuela Grazziotin. Uma reflexão filosófica da ética e do direito na construção de um meio ambiente sustentável. Revista Eletrônica Direito e Política, Programa de Pós-Graduação Stricto Sensu em Ciência Jurídica da UNIVALI, Itajaí, v.10, n.3, 2o quadrimestre de 2015. Disponível em: www.univali.br/direitoepolitica - ISSN 1980-7791.

\title{
UMA REFLEXÃO FILOSÓFICA DA ÉTICA E DO DIREITO NA CONSTRUÇÃO DE UM MEIO AMBIENTE SUSTENTÁVEL
}

\author{
A PHILOSOPHICAL REFLECTION OF ETHICS AND LAW IN THE \\ CONSTRUCTION OF A SUSTAINABLE ENVIRONMENT
}

\section{Manuela Grazziotin Lopes ${ }^{1}$}

SUMÁRIO: introdução; 1. Abordagem Ética À Luz da Filosofia; 2. Ética e Direito; 3. Ética Ambiental e Sustentabilidade; Considerações Finais; Referências das fontes citadas

\section{RESUMO}

Objetiva-se com o presente artigo fazer uma análise, com base na ética, da atual sociedade, tendo em vista as questões de direito e a sustentabilidade do planeta. Os questionamentos filosóficos apresentam-se como ferramenta para assegurar um olhar crítico e investigativo no que diz respeito às diferenças, nas mais diversas esferas que envolvem a inserção do homem na sociedade e sua relação com a preservação do planeta. Deste modo, a proposta é demonstrar a real importância dos questionamentos éticos e sua importante relação nas questões de direito e sustentabilidade.

PALAVRAS-CHAVE: Direito; Ética; Filosofia; Meio Ambiente; Sustentabilidade.

\section{ABSTRACT}

Purpose is to achieve with this article make an analysis, based on the ethics of contemporary society, considering the points of law and the sustainability of the planet. Philosophical questions are presented as a tool to ensure a critical and investigative look with regard to differences in the most diverse spheres involving the insertion of man in society and its relationship to the preservation of the planet. Thus, the proposal is to show the real importance of the ethical questions and their important relationship in law and sustainability issues.

\footnotetext{
${ }^{1}$ Mestranda em direito pela Universidade de Passo Fundo/RS, advogada, graduada em direito pela Universidade de Passo Fundo - UPF, pós graduada em direito ambiental internacional pela Universidade Federal do Rio Grande do Sul - UFRGS, pós-graduanda do curso de Gestão Empresarial, pela Escola de Administração da Universidade Federal do Rio Grande do Sul- UFRGS.
} 
LOPES, Manuela Grazziotin. Uma reflexão filosófica da ética e do direito na construção de um meio ambiente sustentável. Revista Eletrônica Direito e Política, Programa de Pós-Graduação Stricto Sensu em Ciência Jurídica da UNIVALI, Itajaí, v.10, n.3, 2o quadrimestre de 2015. Disponível em: www.univali.br/direitoepolitica - ISSN 1980-7791.

KEY-WORDS: Law; Ethics; Philosophy; Environment; Sustainability.

\section{INTRODUÇÃO}

A reflexão sobre os valores e condutas sociais e culturais do homem em relação à sociedade e ao planeta, com base no pensamento filosófico, é extremamente importante pois permite ao homem analisar e questionar sobre seu agir dentro do meio social, $o$ que sem dúvidas se reflete nos preceitos pretendidos pela ética.

Nesse contexto, o direito insere-se como regulador e garantidor de preceitos para a convivência do homem na atual sociedade, a qual vive uma crise de valores, tendo em vista que deixou-se de pesar os valores coletivos para analisar apenas os interesses individuais, de modo que as questões éticas e morais foram paulatinamente perdendo valoração junto às sociedades, o que, por sua vez, acabou refletindo numa urgência de mudanças significadas no meio que o homem está inserido, sob pena de a sustentabilidade do planeta tornar-se completamente utópica.

No que tange as questões relativas à sustentabilidade, importa fazer menção a sua extrema e indispensável relevância, pois a partir das concepções apresentadas, espera-se que a reflexão resulte em uma orientação para o agir humano frente à crise ambiental assolada. Os valores éticos devem ser refletidos para que se crie perspectivas de mudanças e conscientização da responsabilidade na preservação do planeta.

A sustentabilidade deve ser pautada por valores éticos, cabendo ao direito impor obrigações ao homem, tendo em vista que os recursos finitos não têm capacidade de se renovar na mesma velocidade da exploração.

Assim, a questões éticas e de direito levantadas, apontam para uma reflexão crítica sobre os valores que sustentam a atual situação, garantindo uma transformação e a possibilidade efetiva de sustentabilidade 
LOPES, Manuela Grazziotin. Uma reflexão filosófica da ética e do direito na construção de um meio ambiente sustentável. Revista Eletrônica Direito e Política, Programa de Pós-Graduação Stricto Sensu em Ciência Jurídica da UNIVALI, Itajaí, v.10, n.3, 2o quadrimestre de 2015. Disponível em: www.univali.br/direitoepolitica - ISSN 1980-7791.

Por fim, o presente estudo permite analisar inicialmente alguns aspectos pertinentes ao conceito e abrangência da filosofia ética, para em seguida verificar algumas ponderações sobre o direito, e ao final, algumas considerações sobre a sociedade contemporânea e a sustentabilidade.

\section{ABORDAGEM ÉTICA À LUZ DA FILOSOFIA}

Inicialmente, é importante salientar os conceitos básicos a respeito do que consiste a ética, especialmente no âmbito da filosofia. Para Angelo Vitorio Cenci,

A ética, desde suas origens, busca estudar e fornecer princípios orientadores para o agir humano. Ela nasce amparada no ideal grego de justa medida, do equilíbrio nas ações. A justa medida é a busca do agenciamento do agir humano de tal forma que o mesmo seja bom para todos, isto é, que todos os indivíduos ou cada parte nele envolvido seja contemplada de forma equânime. O espaço de cada indivíduo ou de cada parte que se envolve na ação necessita ser garantido de maneira autônoma e racional.tais princípios indicam não para a perfeição do agir, mas sim para que o mesmo ocorra da melhor forma possível, ou seja, da maneira mais adequada possível. ${ }^{2}$

Nesse sentido, o autor referido quer dizer que a ética desperta situações que dizem respeito ao modo de agir do ser humano, mencionado ser fácil pensar num sentido negativo, isto é, afirmar como as pessoas não deveriam ter agido. Logo, deve-se indicar de forma clara o que é esse agir eticamente.

A ética consiste na obrigação das pessoas de imaginar o que seria mais correto ao realizar o seu ato. No entanto, Cenci entende que "o agir humano pode variarem cada circunstância" e que existem alguns princípios que devem orientar esse agir. Disso se depreende que o agir universal acaba por refletir no particular.

Nesse caso se denota uma relação com os princípios de Immanuel Kant, o qual menciona que deve-se agir de tal sorte que os procedimentos utilizados se

\footnotetext{
${ }^{2}$ CENCI, Angelo Vitório. $\mathbf{O}$ que é ética? Elementos em torno de uma ética geral. 3. ed. Passo
} Fundo: A. V. Cenci, 2002. p. 9. 
LOPES, Manuela Grazziotin. Uma reflexão filosófica da ética e do direito na construção de um meio ambiente sustentável. Revista Eletrônica Direito e Política, Programa de Pós-Graduação Stricto Sensu em Ciência Jurídica da UNIVALI, Itajaí, v.10, n.3, 2o quadrimestre de 2015. Disponível em: www.univali.br/direitoepolitica - ISSN 1980-7791.

tornem regra universal, esse é o imperativo categórico. ${ }^{3}$ Logo, "temos que poder querer que uma máxima da nossa acção se transforme em lei universal: é este o cânone pelo qual a julgamos moralmente em geral". ${ }^{4}$

Seguindo o pensamento de Kant, o professor doutor Márcio Hamel refere que

Na teoria moral kantiana, o imperativo categórico não deriva da experiência e impõe-se por si mesmo, e não pela finalidade que permite agir. O imperativo categórico, cumprido ou não, sempre terá o caráter de lei prática, sendo uma proposição construída por Kant, a qual impõe ao sujeito um imperativo (uma máxima) que deve ser cumprida por enunciar uma lei universal.

Ainda no plano moral, Kant desenvolve o tema da autonomia da vontade, que significa não escolher senão de modo que as máximas da escolha estejam incluídas, concomitantemente, no próprio querer, como uma lei universal. $^{5}$

Com fundamento na ética, se observa que esta fornece os princípios orientadores para um agir de forma justa no equilíbrio das ações, ou seja, o agir humano deve ser de tal forma, que seja bom para todos.

Por evidência, para o ser humano compreender o seu agir, é de fundamental importância a tomada de consciência, pois a ação inconsciente pode trazer graves consequências.

Por conseguinte, não se pode esquecer da concepção de ética em Aristóteles, que vinculava esta às virtudes morais e ao agir. Para ele, a justa medida está vinculada às virtudes. Nesse sentido, Aristóteles refere que "é mediante a prática de atos justos que o homem se torna justo, e é mediante a prática de atos

\footnotetext{
${ }^{3}$ KANT, Immanuel. Fundamentação da Metafísica dos Costumes. Lisboa: Edições 70, 2005. p. 59.

${ }^{4}$ KANT, Immanuel. Fundamentação da Metafísica dos Costumes. 2005. p. 62.

5 HAMEL, Marcio Renan. Da ética kantiana à ética habermasiana: implicações sóciojurídicas da reconfiguração discursiva do imperativo categórico. In: R. Katál, Florianópolis, v. 14, n. 2, p. 164-171, jul./dez. 2011.
} 
LOPES, Manuela Grazziotin. Uma reflexão filosófica da ética e do direito na construção de um meio ambiente sustentável. Revista Eletrônica Direito e Política, Programa de Pós-Graduação Stricto Sensu em Ciência Jurídica da UNIVALI, Itajaí, v.10, n.3, 2o quadrimestre de 2015. Disponível em: www.univali.br/direitoepolitica - ISSN 1980-7791.

moderados que o homem se torna moderado; sem os praticar ninguém teria sequer remotamente a possibilidade de tornar-se bom". 6

Neste contexto, Cenci ao falar sobre a concepção aristotélica da ética, diz que a mesma é fundamentada nas virtudes, principalmente as morais (a justiça e a coragem) e estão vinculadas à formação das pessoas, bem como, as virtudes intelectuais que estão ligadas à razão (sabedoria). ${ }^{7}$

Portanto, é nas virtudes morais que se localizam às virtudes éticas. Nesse caso, as virtudes éticas são provenientes de uma prática de vida, mediante um exercício contínuo, por isso, elas são adquiridas e devem ser desenvolvidas através do hábito, ou seja, por meio de uma prática permanente por atos íntegros.

Deve-se destacar que na visão de Aristóteles, o agir virtuoso tem como pressuposto básico, três aspectos: o agir consciente; o agir deliberadamente; o agir fundamentado em uma disposição moral. Deve-se levar em consideração que esses aspectos são os que fundamentam a escolha ou uma decisão do sujeito (racional). ${ }^{8}$

Ao analisar essa concepção Aristotélica, conclui-se que não há atos virtuosos sem uma devida escolha. Essa opção e decisão, pressupõem um agir consciente e deliberado, afinal, com a deliberação é que a pessoa consegue realizar as diferentes ações e os meios para alcançar o fim. A escolha, por sua vez, é um ato realizado de forma consciente, por isso, é incompreensível a existência do homem que age mal, quando ele possui ao seu alcance a possibilidade de agir bem. Desconsiderando isso, ele pode ser responsabilizado moralmente pelos seus procedimentos.

Por outro lado, sabe-se que o homem age mediante motivos e intenções com o intuito de buscar o fim pretendido. Nesse caminho, depara-se com princípios

6 ARISTÓTELES. Ética a Nicômacos. Trad. de Mário da Gama Kury. 3. Ed. Brasilia: Editora Universidade de Brasília, 1992. p.39.

${ }^{7}$ CENCI, Angelo Vitório. $\mathbf{O}$ que é ética? Elementos em torno de uma ética geral. 2002. p. 22.

${ }^{8}$ ARISTÓtELES. Ética a Nicômacos. Trad. de Mário da Gama Kury. 3. Ed. Brasilia: Editora Universidade de Brasília, 1992. p. 39 
LOPES, Manuela Grazziotin. Uma reflexão filosófica da ética e do direito na construção de um meio ambiente sustentável. Revista Eletrônica Direito e Política, Programa de Pós-Graduação Stricto Sensu em Ciência Jurídica da UNIVALI, Itajaí, v.10, n.3, 2o quadrimestre de 2015. Disponível em: www.univali.br/direitoepolitica - ISSN 1980-7791.

norteadores de escolhas e conseqüências, de forma que as boas ou más escolhas, refletem no próprio homem, como também na sociedade como um todo.

Como consequência, a ética possui uma ocupação de bem orientar as normas morais para o agir. Nesse sentindo, Cenci refere que

A ética diz respeito mais diretamente a uma reflexão formal acerca dos princípios que criticam ou dão legitimidade ao agir humano. Ela fornece parâmetros para se optar pelo o que fazer. É uma reflexão (justificação crítica) do agir e ocupa-se não do ser, com o que é (o fático, aquilo que está em vigência), mas do dever ser, (aquilo que pode ser válido, isto é, justificável racionalmente). Isso não significa que a ética não se ocupe das normas. A ética ocupa-se sim das normas, mas enquanto reflexão formal sobre elas; o que indica é que as normas devem basear-se em princípios universais. $^{9}$

Existem valores e costumes que podem se transformar em normas em face do caráter universal daqueles, bem como o fato de que as normas também desejam a pretensão de universalidade. Nessa situação, as normas possuem na sua essência sempre um deve ser, servindo, como elemento balizador e orientador do agir, especialmente para que esse seja racional.

A ética é a figura norteadora que se preocupa com a forma do agir humano, orientando-o para uma ação correta, preocupando-se com a forma do agir, baseando-se em princípios, valores, costumes ou nas normas. O fato de o homem possuir o livre arbítrio supõe que cabe a ele dispor do seu agir, porém contrariando as normas das relações. Com relação ao livre arbítrio do homem, Kant explica que

[...] 'livre arbítrio' a escolha que pode ser determinada pela razão pura, a que pode ser determinada somente pela inclinação (impulso sensível, estímulo) seria o arbítrio animal (arbitrium brutum). O arbítrio humano é uma escolha que, embora possa ser realmente afetada por impulsos, não pode ser determinada por estes, sendo, portanto, de per si (à parte de uma competência da razão) não pura, podendo,

\footnotetext{
${ }^{9}$ CENCI, Angelo Vitório. 0 que é ética? Elementos em torno de uma ética geral. 2002. p. 46.
} 
LOPES, Manuela Grazziotin. Uma reflexão filosófica da ética e do direito na construção de um meio ambiente sustentável. Revista Eletrônica Direito e Política, Programa de Pós-Graduação Stricto Sensu em Ciência Jurídica da UNIVALI, Itajaí, v.10, n.3, 2o quadrimestre de 2015. Disponível em: www.univali.br/direitoepolitica - ISSN 1980-7791.

não obstante isso, ser determinada às ações pela vontade pura. ${ }^{10}$

Não se pode deixar de mencionar a relação entre a moral e a ética, a primeira está vinculada aos costumes, valores e normas em determinado instante da sociedade, adquirindo, assim, caráter histórico. A ética por sua vez, possui relação direta com o agir humano, isto é, traz à tona os elementos norteadores para que se possa optar pelas escolhas.

Nesse sentido, Leonardo Boff afirma que

Hoje as relações são extremamente complexas. Postula-se uma referência para a totalidade dos seres humanos, habitantes do mesmo planeta, que agora se descobrem como espécie, interdependentes, vivendo numa mesma casa e com um destino comum. Se não criarem um acordo quanto a exigências éticas e morais mínimas, como poderão coexistir pacificamente, preservar o lar comum e garantir um futuro para todos? ${ }^{11}$

Como pode ser observado, a ética e a moral, são princípios que provêm desde os primórdios. Estes princípios sempre foram objeto de estudo na perspectiva do indivíduo ou da coletividade, pois somente mediante eles poderá ser constituída uma sociedade justa.

Diante disso, percebe-se que a ética e a moral tem uma relação de extrema importância, tendo em vista que são através de atitudes éticas e moralmente certas que as relações no mundo podem tornar-se mais harmônicas e justas. Dessa forma, pode-se pensar na ética também com relação ao direito, assunto que será analisado no tópico seguinte.

${ }^{10}$ KANT, Immanuel. A metafísica dos costumes. Tradução de Edson Bini. Bauru: Edipro, 2003. P. 63.

${ }^{11}$ BOFF, Leonardo. Ethos mundial: um consenso mínimo entre os humanos. Rio de Janeiro: Record, 2009. p. 29. 
LOPES, Manuela Grazziotin. Uma reflexão filosófica da ética e do direito na construção de um meio ambiente sustentável. Revista Eletrônica Direito e Política, Programa de Pós-Graduação Stricto Sensu em Ciência Jurídica da UNIVALI, Itajaí, v.10, n.3, 2o quadrimestre de 2015. Disponível em: www.univali.br/direitoepolitica - ISSN 1980-7791.

\section{2. ÉTICA E DIREITO}

A ética é fator importante e se apresenta como referencial para a formação da consciência humana e jurídica, principalmente pela aplicação de regras morais no comportamento social e, também, na valoração das decisões de uma sociedade, de forma que esse caráter normativo da ética o colocará em conexão com o direito.

O direito nasce do mesmo espírito do qual nascem os deveres, para conservar e desenvolver as relações morais, ou seja, os bens éticos, protegendo as condições, onde se realiza, através da força, tudo isso é ético. Para tanto, o direito ora reprime as ações contrárias à conservação e ao desenvolvimento da Ética e ora impõe determinadas ações necessárias. ${ }^{12}$

Assim, a sociedade busca na ética e no resgate dos valores morais uma liberdade igualitária, onde a moral e o direito positivo, que dependem de uma fundamentação, encontrem-se numa relação recíproca e complementar. ${ }^{13}$

Na busca de valores, Habermas refere que a fundamentação que se dá sob o ponto do agir humano deve ser, sobretudo, racional. O autor refere que

[...] todo agir humano, para poder ter valor moral, deve, pois, ter uma base crítica e racional, ou seja, deve buscar e poder ser justificado racionalmente. Como reflexão crítica acerca de princípios e formas de vida, a ética visa fundamentalmente, formar indivíduos autônomos, livres, racionais, capazes de justificar por si próprios e com boas razões o seu agir. ${ }^{14}$

Tendo em vista que a ética, dentro de uma autonomia humana, trata do regate dos valores morais, o direito busca efetivamente regular as relações de um todo,

\footnotetext{
12 BROCHADO, Mariá. Direito e ética: a eticidade do fenômeno jurídico. São Paulo: Landy Editora, 2006, p. 47.

${ }^{13}$ HABERMAS, Jürgen. Direito e democracia: entre a facticidade e validade. 2. Ed. Tradução: Flávio Beno Siebeneichler. Rio de Janeiro: Tempo Brasileiro. 2003, p. 141.

${ }^{14}$ CENCI, Angelo Vitório. Ética Geral e das profissões. Ijuí: Ed. Unijuí. 2010. p.37.
} 
LOPES, Manuela Grazziotin. Uma reflexão filosófica da ética e do direito na construção de um meio ambiente sustentável. Revista Eletrônica Direito e Política, Programa de Pós-Graduação Stricto Sensu em Ciência Jurídica da UNIVALI, Itajaí, v.10, n.3, 2o quadrimestre de 2015. Disponível em: www.univali.br/direitoepolitica - ISSN 1980-7791.

de modo que o agir humano atue dentro de um padrão, de forma a tornar possível a convivência de um todo. E como o direito está situado simultaneamente nos níveis da cultura e da sociedade, ele pode compensar as fraquezas de uma moral racional. ${ }^{15}$

Faz-se então uma reflexão da interligação de ambos e percebe-se que o direito busca uma resposta para a crise de valores que se instaurou na sociedade. Busca-se uma reelaboração das concepções, que possam trazer novos sentidos para a sociedade contemporânea, a fim de compatibilizar os indivíduos com o todo.

Nesse sentido, Bosselmann diz: "A ética sob qualquer forma, deve ser entendida como informação de qualquer idéia de justiça. Não há justiça sem alguma moralidade subjacente, assim como não há direitos humanos sem pressupostos éticos ${ }^{\prime 16}$

Seguindo esse ponto de vista, importa referir o entendimento do autor Angelo Cenci, o qual afirma que
A dimensão moral é fundamental para que uma determinada sociedade seja justa. As normas jurídicas são necessárias e importantes, mas não suficientes para tanto. As leis requerem, antes de qualquer condição, a convicção moral dos sujeitos. ${ }^{17}$

Deste modo, busca-se uma sociedade de indivíduos capazes de evoluir no ponto de vista ético-moral, que oriente-se de princípios comuns, e que através do direito busque regrar e proteger tudo que diz respeito ao bem comum.

A partir disso, pode-se entender que "A ética, sob qualquer forma, deve ser entendida como informação de qualquer idéia de justiça. Não há justiça sem

\footnotetext{
${ }^{15}$ HABERMAS, Jürgen. Direito e democracia: entre a facticidade e validade. 2003, p. 150.

${ }^{16}$ BOFF, Leonardo. Ethos mundial: um consenso mínimo entre os humanos. 2009. p.121.

${ }^{17}$ CENCI, Angelo Vitório. O que é ética? Elementos em torno de uma ética geral. 2002. p.55.
} 
LOPES, Manuela Grazziotin. Uma reflexão filosófica da ética e do direito na construção de um meio ambiente sustentável. Revista Eletrônica Direito e Política, Programa de Pós-Graduação Stricto Sensu em Ciência Jurídica da UNIVALI, Itajaí, v.10, n.3, 2o quadrimestre de 2015. Disponível em: www.univali.br/direitoepolitica - ISSN 1980-7791.

alguma moralidade subjacente, assim como não há direitos humanos sem pressupostos éticos"18

Nesse sentido, com maestria o Professor Doutor Márcio Renan Hamel, menciona um pensamento de Habermas:

A partir de Habermas, a ética passa a implicar coletivamente, remodelando também a esfera pública, que deve ser pluralista com forte conseqüência para as relações sociais, consubstanciado, ainda, uma realocação do direito moderno aliado a uma nova função, qual seja, de garantir as regras democráticas de participação popular. ${ }^{19}$

Entretanto, sabe-se que é direito do homem a garantia de seus direitos sociais, a par que, depara-se com o problema de falta de exigibilidade desse direito. Nesse sentido Bobbio, inteligentemente refere: "o problema fundamental em relação aos direitos do homem, hoje, não é tanto o de justificá-los, mas o de protegêlos. Trata-se de um problema não filosófico, mas político."20

Do ponto de vista da ética da responsabilidade, Boff menciona o seguinte:

Trata-se da sobrevivência de todos, seres humanos, demais seres vivos e da Terra como sistema integrador de subsistemas. O ser humano faz-se corresponsável, juntamente com as forças diretivas do universo e da natureza, pelo destino da humanidade e de sua casa comum, o planeta Terra. ${ }^{21}$

Resta evidente, também, a necessidade de atrelar os direitos dos homens à ética e responsabilidade, já que "não se trata de saber quais e quantos são esses direitos, qual é sua natureza e seu fundamento, se são direitos naturais ou históricos, absolutos ou relativos, mas sim qual o modo mais seguro para garanti-los $[\ldots]^{\prime \prime 22}$

18 BOSSELMANN, Klaus. O principio da sustentabilidade: transformando direito e governança. Tradução: Phillip Gil França. São Paulo. Editora Revista dos Tribunais. 2015, p.121.

19 HAMEL, Marcio Renan. Da ética kantiana à ética habermasiana: implicações sóciojurídicas da reconfiguração discursiva do imperativo categórico. 2011, p. 165.

${ }^{20}$ BOBBIO, Norberto. A era dos direitos. Rio de Janeiro: Campus, 1992, p. 24.

${ }^{21}$ BOFF, Leonardo. Ethos mundial: um consenso mínimo entre os humanos. 2009. p. 92.

${ }^{22}$ BOBBIO, Norberto. A era dos direitos. Rio de Janeiro: Campus, 1992, p. 25. 
LOPES, Manuela Grazziotin. Uma reflexão filosófica da ética e do direito na construção de um meio ambiente sustentável. Revista Eletrônica Direito e Política, Programa de Pós-Graduação Stricto Sensu em Ciência Jurídica da UNIVALI, Itajaí, v.10, n.3, 2o quadrimestre de 2015. Disponível em: www.univali.br/direitoepolitica - ISSN 1980-7791.

Desta forma, além de um agir com eticidade e responsabilidade, as condutas do homem devem ser baseadas no respeito ao próprio ser e o meio que habita, pois o homem, ao usufruir de sua liberdade, deve ter como princípio básico o respeito, para que possa usufruir dos seus direitos sem necessitar da intervenção das leis.

Nesse sentido o professor Elton Luiz Leite de Souza, traduz o pensamento do filósofo Immanuel Kant, de maneira muito interessante, senão vejamos:

[...] O único motivo que deve pautar nossa conduta é o respeito, o respeito é o principal motor da ação livre e moral. Enquanto que no Direito à lei jurídica dá-se por uma obrigação externa à própria vontade do homem (e o descumprimento da lei enseja a coação por parte do poder constituído), na Moral o respeito à lei é um fim em si mesmo: isto é, não respeito a lei com medo da coação ou para parecer melhor que os outros. Ao contrário, respeito a lei por puro Dever. Não faço respeito à lei um meio para obter vantagens ou favorecimento. Em suma, o respeito à lei é um fim em si mesmo. Somente quando a vontade toma a lei como um fim em si mesmo (e não como meio para alguma coisa) é que ela é verdadeiramente autônoma, isto é, livre. 23

Para tanto, a necessidade de resgatar os princípios e valores bons do homem, atrelado à responsabilidade e respeito, são de suma importância para a reformulação e resgate da convivência do homem em sociedade e como habitante do planeta, uma vez que anseia-se por um ambiente equilibrado e sustentável.

\section{3. ÉTICA AMBIENTAL E SUSTENTABILIDADE}

As questões éticas e de valores humanos ganham cada vez mais importância no atual contexto da sociedade contemporânea e tornaram-se fundamentais para o desenvolvimento sustentável.

${ }^{23}$ SOUZA, Elton Luiz Leite de. Filosofia do direito, ética e justiça: filosofia contemporânea. Porto Alegre: Núria Fabris Ed. 2007, p. 124. 
LOPES, Manuela Grazziotin. Uma reflexão filosófica da ética e do direito na construção de um meio ambiente sustentável. Revista Eletrônica Direito e Política, Programa de Pós-Graduação Stricto Sensu em Ciência Jurídica da UNIVALI, Itajaí, v.10, n.3, 2o quadrimestre de 2015. Disponível em: www.univali.br/direitoepolitica - ISSN 1980-7791.

Nesse sentido, é na responsabilidade da coletividade humana e na preservação do meio ambiente onde a ética ambiental se traduz no sistema jurídico como normas e leis, que constituem compromissos a serem exercidos por todos.

As leis se traduzem como forma de evitar desequilíbrios que geram conflitos, e a ética aparece como reguladora de valores humanos, que atrelados, lutam por uma sociedade sustentável.

Em relação ao conceito de sustentabilidade, Enrique Leff menciona: "O conceito de sustentabilidade surge, portanto, do reconhecimento da função de suporte da natureza, condição e potencial do processo de produção e consumo, e marcando os limites do crescimento econômico."24

Ainda, o mesmo autor afirma que

O discurso da "sustentabilidade" leva, portanto a lutar por um crescimento sustentado, sem uma justificação rigorosa da capacidade do sistema econômico de internalizar as condições ecológicas e sociais (de sustentabilidade, eqüidade, justiça e democracia) deste processo. A ambivalência do discurso da sustentabilidade surge da polissemia do termo sustainability, que integra dois significados: um, que se traduz em castelhano como sustentable, que implica a internalização das condições ecológicas de suporte do processo econômico, outro, que aduz a durabilidade do próprio processo econômico. Neste sentido, a sustentabilidade ecológica constitui uma condição da sustentabilidade do processo econômico. (grifo do autor $)^{25}$

Logo, "essa sustentabilidade importa em transformações tanto sociais como econômicas, políticas, jurídicas, porque, em caso contrário, haverá a discrepância entre as instituições existentes sem soluções adequadas". ${ }^{26}$

${ }^{24}$ LEFF, Enrique. Saber ambiental: sustentabilidade, racionalidade, complexidade, poder. Tradução de Lúcia Mathilde Endlich Orth. Petrópolis, RJ : Vozes, 2001. p. 15.

25 LEFF, Enrique. Saber ambiental: sustentabilidade, racionalidade, complexidade, poder. 2001. p. 19-20.

26 PEREIRA, Agostinho Oli Koppe; CALGARO, Cleide; KOPPE, Henrique Mioranza Koppe. A sustentabilidade ambiental e a teoria dos sistemas na sociedade transnacional. In: Revista NEJ Eletrônica, Vol. 17 - n. 1 - p. 70-83 / jan-abr 2012. Disponível em: www.univali.br/periodicos. 
LOPES, Manuela Grazziotin. Uma reflexão filosófica da ética e do direito na construção de um meio ambiente sustentável. Revista Eletrônica Direito e Política, Programa de Pós-Graduação Stricto Sensu em Ciência Jurídica da UNIVALI, Itajaí, v.10, n.3, 2o quadrimestre de 2015. Disponível em: www.univali.br/direitoepolitica - ISSN 1980-7791.

Assim, importa discorrer sobre essa união de forças, que resultam na preservação de interesses coletivos. Nesse sentido, o autor Carlos Josaphat, refere que: "O supremo desafio lançado à sociedade de hoje, empolgada pelo predomínio do utilitarismo individual e corporativo, está no risco, se não no fato, de volatilizar o sentido da justiça no cadinho superaquecido da ambição e do interesse globalizados". ${ }^{27}$

Sobre os interesses que a globalização impõe, Bosselmann menciona:

Mais especificamente, os objetivos e padrões aplicados centram no ser humano. Os objetivos são a sobrevivência da humanidade, seus padrões de vida e seu uso continuado dos recursos. O estado do meio ambiente é determinado pelas necessidades da humanidade, e não pelas necessidades das outras espécies. ${ }^{28}$

Entretanto, nesse contexto de sociedade globalizada, muitas vezes menosprezam-se as questões ambientais, que podem ser vistas até como barreira ao desenvolvimento econômico, de forma que o respeito pelo meio ambiente deve suprir as irresponsabilidades, a fim de que o desenvolvimento sustentável deva prevalecer acima dos demais interesses, tendo em vista a necessidade de recursos que beneficiem a atual e as próximas gerações.

Em relação a isso, Leff entende que

A resistência à globalização implica a necessidade de desativar o poder de simulação e perversão das estratégias desta nova ordem econômica. Para isto é necessário construir uma racionalidade social e produtiva que, reconhecendo o limite como condição de sustentabilidade, funde a produção nos potenciais da natureza e da cultura. ${ }^{29}$

Nesse sentido, Boff menciona que

27 JOSAPHAT, Carlos. Ética mundial esperança da humanidade globalizada. Editora Vozes Ltda. Petrópolis RJ. 2010, p. 317.

28 BOSSELMANN, Klaus. O principio da sustentabilidade: transformando direito e governança, 2015, p.163.

${ }^{29}$ LEFF, Enrique. Saber ambiental: sustentabilidade, racionalidade, complexidade, poder. 2001. p. 28. 
LOPES, Manuela Grazziotin. Uma reflexão filosófica da ética e do direito na construção de um meio ambiente sustentável. Revista Eletrônica Direito e Política, Programa de Pós-Graduação Stricto Sensu em Ciência Jurídica da UNIVALI, Itajaí, v.10, n.3, 2o quadrimestre de 2015. Disponível em: www.univali.br/direitoepolitica - ISSN 1980-7791.

Para uma realidade global, importa também uma ética global. Até agora predominava uma ética traduzida nas várias morais, próprias de cada cultura ou região do planeta. Elas não ficam invalidadas, pois determinam valores, normas e práticas do ser humano em seu arranjo existencial, social e ecológico concreto. Todas nasceram da reflexão humana sobre o ethos, que é da natureza universal. O ethos configura a atitude de responsabilidade e de cuidado com a vida, com a convivência societária, com a preservação da Terra, com cada um dos seres nela existentes e com a identificação de um derradeiro sentido do universo. Esse ethos básico se traduz em morais ligadas ao regional e cultural e, por isso, com validade limitada ao regional e ao cultural. $^{30}$

A transmissão dos valores ecológicos por meio da ética pode nortear uma mudança de comportamento em direção a padrões mais sustentáveis, de forma a viabilizar o desenvolvimento econômico e minimizar a exploração dos recursos naturais de maneira mais sustentável.

As éticas de preservação apontam para valores nãomateriais da natureza. Para essas éticas, a natureza detém, antes de mais nada, um valor científico, pois fornece conhecimentos inestimáveis para a pesquisa da verdade, para encontrar a excelência moral do ser humano, para fornecer normas de comportamento. Enfim, o estudo da natureza possibilita a formulação de uma ética natural. ${ }^{31}$

Nesse contexto, emerge a necessidade de uma nova ética, onde se reflita diante da crise existente no mundo, na qual as pessoas entendam que suas ações geram consequências muitas vezes irreversíveis.

Assim, urge-se por uma reformulação do crescimento desenfreado, a fim de torna-se sustentável, para que as gerações futuras também possam usufruir dos recursos naturais e de um meio ambiente equilibrado.

\footnotetext{
${ }^{30}$ BOFF, Leonardo. Ethos mundial: um consenso mínimo entre os humanos. Rio de Janeiro: Record, 2009. p. 23.

31 JUNGES, José Roque. Ética ambiental. São Leopoldo: Editora Unisinos. 2014, p. 17.
} 
LOPES, Manuela Grazziotin. Uma reflexão filosófica da ética e do direito na construção de um meio ambiente sustentável. Revista Eletrônica Direito e Política, Programa de Pós-Graduação Stricto Sensu em Ciência Jurídica da UNIVALI, Itajaí, v.10, n.3, 2o quadrimestre de 2015. Disponível em: www.univali.br/direitoepolitica - ISSN 1980-7791.

\section{CONSIDERAÇÕES FINAIS}

Percebe-se que para que haja um desenvolvimento sustentável no mundo atual, a ética ambiental é que vai nortear as condutas e o agir humano para que isso aconteça. O direito é necessário para regular determinadas condutas, através de uma legislação ambiental que possibilite esse desenvolvimento sustentável.

A sustentabilidade ganha validade diante da conscientização, pelo despertar de uma nova preocupação que dê conta dos desafios e contradições apresentados pela sociedade contemporânea, que busca cada vez mais apenas desenvolver-se economicamente.

Diante do cenário caótico que se apresenta, é preciso despertar valores éticos de responsabilidade, a fim de que se crie relações mais estreitas com a natureza. Assim, depois do breve descrito, cabe a todos uma reflexão sobre as questões filosóficas e de direito apresentadas, uma vez que a sustentabilidade precisa ser vista como direito fundamental das atuais e futuras gerações.

\section{REFERÊNCIAS DAS FONTES CITADAS}

ARISTÓTELES. Ética a Nicômacos. Trad. de Mário da Gama Kury. 3. Ed. Brasilia: Editora Universidade de Brasília, 1992.

BOBBIO, Norberto. A era dos direitos. Rio de Janeiro: Campus, 1992.

BOFF, Leonardo. Ethos mundial: um consenso mínimo entre os humanos. Rio de Janeiro: Record, 2009.

BOSSELMANN, Klaus. O principio da sustentabilidade: transformando direito e governança, 2015.

BROCHADO, Mariá. Direito e ética: a eticidade do fenômeno jurídico. São Paulo: Landy Editora, 2006, 
LOPES, Manuela Grazziotin. Uma reflexão filosófica da ética e do direito na construção de um meio ambiente sustentável. Revista Eletrônica Direito e Política, Programa de Pós-Graduação Stricto Sensu em Ciência Jurídica da UNIVALI, Itajaí, v.10, n.3, 2o quadrimestre de 2015. Disponível em: www.univali.br/direitoepolitica - ISSN 1980-7791.

CENCI, Angelo Vitório. O que é ética? Elementos em torno de uma ética geral. 3. ed. Passo Fundo: A. V. Cenci, 2002.

HAMEL, Marcio Renan. Da ética kantiana à ética habermasiana: implicações sóciojurídicas da reconfiguração discursiva do imperativo categórico. In: $\mathbf{R}$. Katál, Florianópolis, v. 14, n. 2, p. 164-171, jul./dez. 2011.

JOSAPHAT, Carlos. Ética mundial esperança da humanidade globalizada. Editora Vozes Ltda. Petrópolis RJ. 2010.

JUNGES, José Roque. Ética ambiental. São Leopoldo: Editora Unisinos, 2014.

KANT, Immanuel. A metafísica dos costumes. Tradução de Edson Bini. Bauru: Edipro, 2003.

, Immanuel. Fundamentação da Metafísica dos Costumes. Lisboa: Edições 70, 2005.

LEFF, Enrique. Saber ambiental: sustentabilidade, racionalidade, complexidade, poder. Tradução de Lúcia Mathilde Endlich Orth. Petrópolis, RJ: Vozes, 2001.

SOUZA, Elton Luiz Leite de. Filosofia do direito, ética e justiça: filosofia contemporânea. Porto Alegre: Núria Fabris Ed., 2007.

Submetido em: Abril/2015

Aprovado em: Julho/2015 